\title{
Labyrinthe
}

25 | 2006 (3)

La Bande dessinée : ce qu'elle dit, ce qu'elle montre

\section{Cut-up et déconstruction}

Éléments d'introduction à une étude comparée

\section{Clémentine Hougue}

\section{(2) OpenEdition}

Journals

Édition électronique

URL : http://journals.openedition.org/labyrinthe/1422

DOI : $10.4000 /$ labyrinthe. 1422

ISSN : 1950-6031

Éditeur

Hermann

Édition imprimée

Date de publication : 1 décembre 2006

Pagination : 127-131

ISBN : 2-9526131-2-5

Référence électronique

Clémentine Hougue, " Cut-up et déconstruction », Labyrinthe [En ligne], 25 | 2006 (3), mis en ligne le 28 mars 2010, consulté le 19 avril 2019. URL : http://journals.openedition.org/labyrinthe/1422 ; DOI : $10.4000 /$ labyrinthe.1422

Ce document a été généré automatiquement le 19 avril 2019

Propriété intellectuelle 


\title{
Cut-up et déconstruction
}

\author{
Éléments d'introduction à une étude comparée
}

\section{Clémentine Hougue}

Calling partisans of all nations - Word falling -

Photo falling - Break through in Grey Room Pinball led streets - Free doorways - Shift coordinate points. Alerte aux partisans de toutes les nations - Mot tombant - Photo tombant - Irruption dans la Chambre grise Rue conduite par les billards électriques - Portières gratuites - Déplacez les points de coordination ${ }^{1}$.

1 Le nom de William Burroughs (1914-1997) est le plus souvent associé à des thématiques contestataires, qu'alimente largement sa sulfureuse biographie; on parle moins en revanche de l'importance de la réflexion sur le langage élaborée par ses recherches théoriques*. Le cut-up, technique d'écriture qu'il met au point avec le poète et peintre Brion Gysin (1916-1986) au début des années 1960, consiste en un agencement de fragments de textes préalablement découpés, les textes utilisés étant aussi bien des créations de Burroughs lui-même et de ses proches (Kerouac, par exemple) que des extraits de Joyce, Rimbaud, Kafka ou Shakespeare. C'est suivant ce procédé que Burroughs écrivit La Machine molle (1960), Nova Express (1962) et Le ticket qui explosa (1964): ladéstructuration de la syntaxe et le morcellement de l'unité textuelle donnent à lire une prose haletante, dont le point de vue « ressemble à l'œil blessé d'une mouche ${ }^{2}$ ». Cette «trilogie » entre en relation avec Euvre croisée (The Third Mind, 1998), un recueil de travaux de Burroughs et Gysin écrits entre 1965 et 1970, qui pose les principaux enjeux du cut-up : mêlant essais, textes de fiction, synopsis de film et photo-montages, cet ouvrage acquiert par sa composition un statut hybride entre texte et méta-texte, à la fois création littéraire et discours sur cette création. Il apparait alors que ces textes, qui n'ont jusqu'ici guère fait l'objet que d'études thématiques (drogue, homosexualité, plus globalement imaginaire et poétique de la marginalité), visent à déconstruire les rapports traditionnels des diverses forces en présence dans le langage (parole/écriture, organique/mécanique, 
dedans/dehors du texte) : aussi la pensée de Jacques Derrida (1930-2004) nous permet-elle d'éclairer d'un jour nouveau le travail de Burroughs et de prendre la mesure de la portée conceptuelle qu'il représente ${ }^{3}$.

Ouvrant à l'écriture de nouveaux champs d'investigation, le cut-up met en question l'origine du langage, interrogation qui se manifeste par une formule obsédante: «Au commencement était le verbe. Au commencement de quoi, au juste?» Fondée sur les premiers mots de l'Évangile selon saint $\mathrm{Jean}^{4}$, la mise en question du «verbe du commencement» dans les cut-ups est omniprésente; il semble qu'il faille y voir l'interrogation de l'existence d'un signifié originel, d'une parole précédant le langage. Cette notion de logos fondateur est le point de départ de toute l'entreprise déconstructrice : c'est là le point d'ancrage d'un rapprochement entre le cut-up et la déconstruction. Cette "métaphysique du langage» que Jacques Derrida nomme le logocentrisme ${ }^{5}$, présente une dévaluation systématique de l'écriture par rapport à la parole, position qui empêche toute philosophie de se départir définitivement de la métaphysique. De Platon à Heidegger, il s'attache ainsi à montrer et " démonter » cette illusion d'une parole pleinement présente à elle-même et à son signifié. Le cut-up semble souligner cette dissociation de l'écriture par rapport au vécu et à la profération, en traitant le texte comme matériau déplaçable, répétable, indépendant de toute présence qui lui préexisterait. Si l'écriture n'est pas pleinement présente à elle-même, si ce qui advient dans le texte n'est pas une parole première, fondatrice et idéelle, c'est alors que le mode de fonctionnement de l'écriture repose sur la non-plénitude, c'est-à-dire sur le différer. Ce différer qui instituerait l'écriture comme telle est un élément qui est à la fois présent et absent : la trace. Dans le cut-up, le morcellement et la répétition de certains fragments dans un texte, ou d'une œuvre à l'autre, exacerbent la visibilité de ce différer. Le texte fuit toujours vers son dehors, déborde ses propres limites. Dans Euvre croisée, Burroughs affirme le caractère fondamental de ce jeu de répétition : «Toute écriture est en fait constituée de cut- ups. Un collage de mots lus et rabâchés. Quoi d'autre? L'utilisation dela paire de ciseaux rend le processus explicite et est susceptible d'extension et de variation ${ }^{6}$.» Cette itérabilité, qui Derrida le trait constitutif de l'écriture et du langage, fait ici l'objet d'un traitement particulier par le degré de systématisation auquel arrive le cut-up : l'écriture y devient un processus mécanique.

3 To cut-up signifie« découper " : nécessitant l'intervention d'un outil,le cut-up serait alors une écriture mécanique. Jacques Derrida, dans Papier Machine, explique que l'on considère traditionnellement que lamachine est sans organicité : elle est répétition, sans désir ni intention, programme calculable n'ayant besoin de personne. Au contraire, l'événement est essentiellement organique. L'écriture telle qu'on l'envisage traditionnellement, comme production d'un auteur, est un événement singulier. Une forme littéraire faisant intervenir une mékhané mettrait au jour une nouvelle logique qui serait à la fois un événement organique et une mécanique inorganique: le cut-up procède de cette déconstruction des antagonismes qui régissent l'écriture. Il rompt toute possibilité d'authentifier une origine, une voix originaire ou une intention préexistant au texte. Il n'y a pas de présent, même un présent révolu, un avoir-été-présent de l'écriture. Chez Derrida comme dans le cut-up, l'écriture est principiellement hétérogène: jamais pleinement présente à elle-même, elle est toujours trace, différance, polysémie. C'est son itérabilité, nécessaire et constitutive, qui induit cette équivocité permanente de l'écriture, et de tout le langage. 
Il semble que ce soit une certaine vision de l'ontologie du texte, ou de la littérature, comme règne du Même et de l'Un, qu'abandonne le cut-up. L'écriture est différence, délai, non-immédiateté. C'est ce qu'affirmeDerrida et ce que Burroughs et Gysin, en appliquant à leurs textes un travail de découpage, de répétition et de fragmentation, mettent au jour. Mais cette différance implique que l'écriture, et tout le langage avec elle, porte en elle sa propre altérité; dans sa venue au jour, sa propre absence : le cut-up instaure l'appréhension sensible de cette absence, dans le sens où le texte découpé rappelle toujours l'absence du texte auquel il appartenait précédemment. Ce type d'écriture manifeste ainsi cette absence sans laquelle aucune écriture n'est possible. Par ailleurs, le principe de répétabilité, ou itérabilité, sur lequel Derrida fait reposer toute possibilité de langage est régi par une logique parasitaire. Dans La Dissémination, le philosopheécrit que«l'hétérogénéitédesécritures, c'estl'écriture elle-même, la greffe. Elle est d'abord nombreuse ou elle n'est pas ${ }^{7}$ ». Ce que met en jeu la pratique du cut-up est en fait inhérent à la structure même de l'écriture : le jeu de citation, de " greffe » et de parasitage dans les textes de Burroughs pousse à son paroxysme une des propriétés « naturelles» du langage. Le parasitage est un processus qui intéresse tout particulièrement Burroughs : tous ses romans, de Junky (1953) à son dernier opus, Mon éducation: un livre des rêves (A Book of Dreams, 1991), présentent une thématique du parasitage biologiqued'un corps par un autre, de la transmission de virus ou d'hybridation entre humain, animal et végétal. Mais le parasitage ne s'arrête pas au niveau thématique puisqu'il régit tout le système narratif : le cut-up repose sur la création de brouillages dans la narration; des interférences aléatoires, issues de la recomposition du texte préalablement découpé, manifestent une cohérence de l'hétérogène en même temps qu'elles déstabilisent la linéarité de la lecture. Le langage est un virus: comme agent de contagion, le virus s'introduit dans un organisme et trouble son fonctionnement ; dire que le langage est un virus, c'est le penser comme un élément qui contamine le sens de l'intérieur. La langue devient alors l'instrument de sa propre contamination et de sa propre mutation.

5 "Faire surgir du texte découpé et réarrangé de nouvelles images ${ }^{8}$ " en montrant le potentiel infiniment renouvelable du texte, telle est l'ambition de Burroughs dans ses expérimentations. Mais plus qu'un simple jeu sur la matérialité de l'écriture, le cut-up pose des questions d'ordre ontologique sur le langage, questions qu'une lecture déconstructiviste permet de mettre au jour. Apparaissant comme une pensée résolument en prise avec les révolutions littéraires du XXe siècle, la philosophie de Derrida offre au travaux de Burroughs et Gysin un réceptacle privilégié où résonnent et s'amplifient les points névralgiques de leur vision de l'écriture.

\section{NOTES}

1. William S. Burroughs, Nova Express, New York, Grove Press, 1992, p. 31. Traduit par Mary Beach et Claude Pélieu et publié en France sous le titre Trilogie, La Machine molle, Le ticket qui explosa, Nova Express, Paris, Christian Bourgois, 1994, p. 372. 
*. Ce texte est le résumé d'un mémoire de Master II de littérature générale et comparée, soutenu en mai 2006 à l'université de Paris III-Sorbonne nouvelle, sous la direction de M. Jean Bessière.

2. Gérard-Georges Lemaire, préface de William S. Burroughs, Trilogie, ibid., p. 21.

3. Le rapprochement entre cut-up et déconstruction est, à notre connaissance, inédit ; toutefois, étant donné le nombre important de publications de Jacques Derrida, un texte traitant de Burroughs ou du cut-up a pu nouséchapper.

4. Saint Jean, Évangile, I, 1 : «Au commencement était le Verbe et le Verbe était avec Dieu et le Verbe était Dieu. - Il était au commencement avec Dieu. Tout fut par lui, et sans lui rien ne fut. De tout être il était la vie, et la vie était la lumière des hommes, et la lumière luit dans les ténèbres et les ténèbres n'ont pu l'atteindre. »

5. Jacques Derrida, De la grammatologie, Paris, Éditions de Minuit, coll. «Critique », 1967, p. 11.

6. Paris, Flammarion, 1976, p. 34-35.

7. Jacques Derrida, Paris, Points Seuil, 1972, p. 396.

8. William S. Burroughs, "The Art of Fiction", interview avec Conrad Knickerbocker, Paris Review, 1966.

\section{AUTEUR}

\section{CLÉMENTINE HOUGUE}

clem1404[at]yahoo.fr 